ARCTIA ARGE, DRURY.

BY PROF. S. H. PEABODY, AMHERST, MASS.

A moth taken by an evening lamp, May 25, 1873 , on that night and the next day laid eggs which hatched June 14 . The larva fed freely on the leaves of the common narrow-leaved plantain, Plantago lanceolata. The earlier moults were not observed with care; the last two occurred June 23 and July $\mathrm{I}$.

July 6 , the larvæ ceased feeding and next day began to spin their cocoons in the breeding cage. July 26 , imagos appeared, copulated and laid eggs for a second brood. Other imagos appeared at about the same time from without, showing the species to be double brooded. The cycle of transformations occupied $4 z$ days from the hatching, 62 from the laying of the egg.

When the larvæ ceased feeding they were $13 / 4$ inches long, $1 / 4$ inch in diameter, tapering slightly to each end.

Head small, black, marked in front with an impressed inverted $X$. Fore legs black; pro-legs yellow with black fringe.

Body dark brown; a white dorsal stripe, and midway to spiracles a white lateral stripe, shaded to orange on each segment; spiracles black ; an orange spot above each, and a wavy white line beneath. Underneath dirty gray; on each segment twelve black tubercles, two on each dark stripe, clothed with long white hairs.

The moth is quite abundant in this locality.

\title{
EDITORIAL SUMMARY.
}

The Butterfles of North Axirica, by W. H. Edrards-'Second Series. - We are much pleased to be able to announce that the first part of the second volume of this admirable work will be issued during the present month, by Messrs. H. O. Houghton \& Co., Riverside Press, Cambridge, Mass., the succeeding parts to appear quarterly, with five plates in each part. The illustrations which adorn the pages of Vol. I are admirably truthful and life-like, and we have no doubt but that the forthcoming volume will in this respect quite equal its predecessor. The talented artists who were engaged upon the plates of the previous volume, 